\title{
UTILIZAÇÃO DE FORRAGENS ORIUNDA DA HORTA ORGÂNICA NA CRIAÇÃO DE COELHOS
}

Using forages from organic garden to raise rabbits

DOI: 10.30612/re-ufgd.v6i11.8792

\author{
${ }^{1}$ Andrea Maria de Araújo Gabriel ${ }^{1}$; \\ ${ }^{1}$ Euclides Reuter de Oliveira; \\ ${ }^{2}$ Willian da Silva Gouvea; \\ ${ }^{3}$ Elaine Barbosa Muniz; \\ ${ }^{1}$ Érika Rosendo de Sena Gandra; \\ ${ }^{1}$ Jefferson Rodrigues Gandra; \\ ${ }^{2}$ Adrielly Aparecida do Carmo; \\ ${ }^{4}$ Thaís Lemos Pereira; \\ ${ }^{4}$ Nara de Medeiros Pordeus; \\ ${ }^{2}$ Gisele Rodrigues de Oliveira Santos.
}

Recebido: 18/09/2018

Aceito: $24 / 08 / 2019$

Resumo: A criação de coelhos pode ser considerada uma atividade que pode trazer benefícios econômicos e ambientais a quem busca ser autosustentável. Esta ação extencionista propôs implantar criação de coelhos em uma perspectiva estratégica de diversificação em propriedades rurais. Para tanto, foi incentivada a criação de coelhos em grupos formados na comunidade de assentados localizado no Assentamento Areias, município de Nioaque-MS e na Escola Familiar Agrícola Rosalvo da Rocha Rodrigues-EFAR/COAAMS, pertencente ao município de Maracaju MS. Estes grupos desenvolvem horticultura com base nas técnicas da produção orgânica, onde existem sobras de hortaliças. Com os resíduos das hortas, parte foi utilizada como alimento para os animais. Assim, via Universidade Federal da Grande, Dourados, foram doados coelhos da raça nova Zelândia ou mestiços, após desmame, com idade média de 45 a 60 dias. Foram efetuados acompanhamento mensal e orientações teóricas e práticas empregadas na atividade, feitas discentes, docentes da UFGD e técnicos da APOMS que orientaram a produção de hortaliças. As instalações para a criação foram rústicas, com as coelheiras, suspensas, feitas de sobras de madeira e os utensílios, mínimo necessário, de plástico. A alimentação dos animais foi constituída de ração e forragem e parte das hortaliças. Dentro de uma perspectiva de diversificação em propriedades rurais, a atividade cunícula se evidencia com grande potencial, visto seus benefícios relacionados à baixa necessidade de espaço, ao aproveitamento de resíduos, impacto ambiental reduzido, fonte rica de proteína e complementaridade com outras atividades. Vale ressaltar ainda que sistema recomendado, o manejo e a linguagem utilizada devem ser adaptados à realidade do público a ser

\footnotetext{
$1^{1}$ Universidade Federal da Grande Dourados, Dourados, MS, andreagabriel@ufgd.edu.br; ${ }^{2}$ Discentes do Curso de Zootecnia da UFGD; ${ }^{3}$ UNIOESTE, Marechal Cândido Rondon, PR, ebmuniz@yahoo.com.br, ${ }^{4}$ Mestrandas d programa de pós-graduação em Produção Animal da UFGD
}

Gabriel et al, p. 05-13 
atingido, diferenciando-se do preconizado para uma criação comercial.

Palavras-Chave: assentados, atividade produtiva, cunicultura, extensão rural, horticultura.

Abstract: Rabbits raising can be considered an activity that can bring economic and environmental benefits to those who seek to be self-sustaining. This extensionist action proposed to implant the cuniculture in a strategic perspective of diversification in rural properties. For this reason, settlers were encouraged to raise rabbits in groups in the community located in the Areias settlement, municipality of Nioaque - MS and in the Escola Familiar Agrícola Rosalvo da Rocha Rodrigues EFAR / COAAMS, an agricultural family school located in Maracaju - MS, Brazil. These groups develop horticulture based on the techniques of organic production, where there is the vegetable waste. Therefore, via the Federal University of Grande Dourados (UFGD), New Zealand or crossbred rabbits were donated, after weaning, with an average age of 45 to 60 days. Monthly monitoring, theoretical and practical orientations were carried out by students and professors of UFGD, and APOMS technicians who guided the vegetable production. The breeding facilities were rustic, with the rabbit hutches suspended, made of leftover wood and the minimum necessary utensils of plastic. The animals feeding consisted on ration, forage and part of the vegetables. From a perspective of diversification in rural properties, the activity is evidenced with great potential, considering its benefits related to the low need of space, the use of the organic garden waste, reduced environmental impact, a rich source of protein and complementarity with other activities. In conclusion, it is important to emphasize that despite of the recommended system, the management and the language used must be adapted to the reality of the public to be reached, differing from the one advocated for a commercial creation.

Key words: settlers, productive activity, rabbits, rural extension, horticulture.

\section{Introdução}

Os coelhos (Oryctolagus cuniculus) são aninais que se destacam pelo seu rápido crescimento, alta fertilidade, precocidade reprodutiva, elevada prolificidade e curto período de gestação, podendo desempenhar um papel importante na alimentação humana, pois, de acordo com os fatores anteriormente mencionados, contribui significativamente para o aumento na produção de carne, alimento de altíssima qualidade nutricional. O coelho é um animal que pode utilizar uma dieta à base de produtos e subprodutos com alto teor de fibra (SCAPINELLO et al., 2000; SANTOS et al., 2006). Além disso, possui o sistema digestório desenvolvido, principalmente o ceco, com ativa ação microbiana, resultando em uma alta capacidade de aproveitamento comparado aos suínos e aves, apresentando boa conversão alimentar com dietas contendo grandes quantidades de forragens (FERREIRA et al., 1997).

Realmente os coelhos possuem um sistema digestivo peculiar sendo considerados animais herbívoros não ruminantes de ceco funcional e praticantes da cecotrofia, ou seja, processo de excreção seletiva da fibra mais lignificada e atividade microbiana simbiótica, utilizando os produtos da fermentação e os próprios corpos bacterianos incorporados aos cecotrofos (OLIVEIRA, 
2009). Esta informação configura como um ponto positivo da cunicultura, uma vez que por se tratar de um pequeno herbívoro monogástrico, o coelho se alimenta facilmente de uma grande variedade de alimentos ricos em celulose. Assim sua fisiologia digestiva contribui para sua adaptação a estruturas rústicas de criação, o que o torna uma proposta atrativa, especialmente quando o objetivo é o de produzir qualidade de proteína animal (ALMEIDA e SACCO, 2012; LUKEFAHR, 2004).

Segundo Schiere e Corstiaensen (2008) em uma criação tradicional, o coelho se beneficiará com o consumo de vegetais, sejam capim, folhas, legumes, etc.., contudo, alguns cuidados deverão ser observados como, por exemplo, deixar estes alimentos, também conhecidos como alimentos grosseiros, murchar durante meio dia antes de fornecê-los aos animais, de forma a evitar que estes tenham alguns transtornos digestivos. Mencionaram também que o produtor tem sorte de ter acesso a folhas de couve, cenouras ou bananas que são descartados, pois poderá aproveita-los. Conforme Machado e Ferreira (2011), sua fisiologia digestiva particularmente potencializada pela cecotrofia, incrementa o aproveitamento dos nutrientes e assim outros subprodutos agroindustriais também podem ser utilizados, podendo muitos deles ser oferecido diretamente ao animal, tais como restos de hortaliças e outros rejeitos hortifrutigranjeiros.

Como destacado por Luzzi (1997), a possibilidade de incorporar diversas alternativas econômicas distintas ao meio rural foi uma estratégia adotada por vários países para manter o homem no campo, com melhoria de sua qualidade de vida por meio do aumento de sua renda, que passa a ser gerada por uma maior diversidade de atividades e funções. Assim conforme Machado (2012), uma dessas alternativas é a cunicultura, atividade com manejo, alojamento e alimentação facilitados, mesmo que ainda pouco praticada no Brasil, possui excelente potencial de crescimento e geração de renda.

MACHADO (2012) e OSENI (2012) destacaram outros aspectos benéficos na criação de coelhos: a)elevada produtividade, b) baixa necessidade de área útil para a criação, c) trabalho/mão-de-obra considerado leve se comparado a outras criações, d) auto-geração de animais para crescimento ou reprodutores, e) aproveitamento de alimentos de baixo valor nutricional, f) geração de esterco de alta qualidade, g) possibilidade do aproveitamento de subprodutos do abate e h) baixa necessidade/consumo de água. Neste sentido, pode-se considerar que a cunicultura possui aspectos benéficos tanto na esfera econômica, como na esfera social e ambiental.

Devido ao seu fácil manejo em sistema de confinamento, por sua docilidade, seu rápido período reprodutivo e pela a diversidade de produtos obtidos, o coelho é um forte competidor dentro de uma perspectiva produtiva, em relação a outras espécies de animais, principalmente como 
fonte de renda alternativa em propriedades rurais que buscam uma diversificação (FABICHAK, 2005; VIEIRA, 2008). A criação de coelhos, conforme a ACBC (2018), apresenta uma importância social valiosa, na medida em que é uma criação que ocupa pequeno espaço, podendo, portanto, ser desenvolvida em pequenas propriedades, integrando-se as demais atividades do produtor. Neste contexto, a criação de pequenos animais pode ser uma operação lucrativa para as pessoas que vivem na área rural, oferecendo trabalho para mulheres, crianças e idosos e sendo uma fonte de proteína tanto para autoconsumo, como para comercialização (MACHADO, 2012; OSENI, 2012).

Com o aumento da aceitação da carne de coelhos para alimentação humana, o aproveitamento da pele para fins industriais e a utilização dos pêlos para preparo de feltros são fatores que contribuem para crescimento da atividade criatória doméstica e industrial. Seja em escala industrial, seja na forma de artesanato caseiro, proporciona uma renda complementar para pequenos produtores por meio da comercialização de peles ou peças produzidas, que constituem o subproduto de maior valor, as patas e a cauda (confecção de amuletos e chaveiros); cérebro e do sangue para obtenção do soro; constituindo uma alternativa econômica da exploração da cunicultura (VIEIRA et al., 2016)

Frente a isso, a cunicultura pode ser implantada em pequenas propriedades ou até mesmo se configurar como uma simples criação caseira de subsistência. E assim objetivou-se, com esta ação, implantar criação de coelhos como estratégia de diversificação na agricultura familiar para aproveitamento de produtos ecologicamente produzidos no campo.

\section{Metodologia}

A ação extensionista teve início com o diagnóstico do público alvo pela aceitação da implantação da criação de coelhos e a melhor forma de desenvolvimento da mesma, uma vez que os interessados em participar são pessoas que produzem hortaliças, como "couve, alface, cenoura, beterraba, almeirão, batata doce, abóbora, amendoim, guandu”, com base nas técnicas da produção orgânica e possuem sobras que eram descartadas. Desta forma vislumbrou-se a possibilidade de agregação da cunicultura na horticultura e os resíduos gerados pela horta se transformariam em coprodutos.

Assim a ação foi desenvolvida no Assentamento Areias, no distrito de Nioaque e também na escola Família Agrícola Rosalvo da Rocha Rodrigues-EFAR/COAAMS, município de Maracaju, ambos localizados no estado de Mato Grosso do Sul, todos envolvidos com horticultura orgânica e acompanhados pelos técnicos da Associação dos Produtores Orgânicos de Mato Grosso 
do Sul (APOMS).

Para o processo de desenvolvimento criação, foram doados coelhos machos e fềmeas, da raça Nova Zelândia ou mestiços, após o desmame, com a idade média de 45 a 60 dias. Os animais doados são oriundos de criação dos projetos da Universidade Federal da Grande Dourados, na cidade de Dourados, MS, onde foram acasalados e acompanhados por alunos do curso de Zootecnia, todos matriculados na disciplina de cunicultura, com a finalidade de se obter esses láparos.

Além das doações dos animais, os discentes e docentes do curso de Zootecnia acompanharam todo o trabalho dos grupos, realizando assim reuniões mensais, enfatizando a organização coletiva e a produção. Os participantes tiveram orientações teóricas e práticas, com conteúdo envolvendo as raças para produção de carne, melhoramento genético, sistemas de produção, instalações, manejo reprodutivo, manejo alimentar, manejo sanitário, controle zootécnico e orientações no plantio das hortas.

Foram utilizados materiais desenvolvidos pelos docentes e discentes, constando de palestras expositivas, textos para discussão em grupo e recomendações técnicas para aplicação em práticas de campo e demais assuntos complementares. A cada etapa foi oferecido informações e estabelecido tarefas práticas que foram cobradas e orientadas nas visitas, que ocorreram mensalmente. Avaliação das atividades, junto aos envolvidos, compreenderam os resultados que foram obtidos em cada etapa de desenvolvimento das ações, avaliando o grau de satisfação, suas necessidades assim como o aproveitamento dos resíduos da horta.

\section{Resultado e Discussão}

Entende-se a extensão como um eixo, uma função acadêmica, e que se entrecruza com outros eixos do fazer acadêmico, dentre eles a pesquisa e o ensino. Por isso corrobora-se com o pensamento apresentado por Edineide Jezine, quando destaca que:

Os princípios da integração ensino-pesquisa, teoria e prática que embasam a concepção de extensão como função acadêmica da universidade, revelam um novo pensar e fazer, que se consubstancia em uma postura de organização e intervenção na realidade, em que a comunidade deixa de ser passiva no recebimento das informações/conhecimentos transmitidos pela universidade e passa a ser, participativa, crítica e construtora dos possíveis modos de organização e cidadania (JEZINE, 2004, p. 3).

Neste sentido, o trabalho de extensão proporcionou ações que pudessem fornecer 
"duas coelhas" e um "coelho macho" para cada local atendido. Os animais levaram três meses, depois de adquiridos, para entrarem em reprodução. Com um ano de criação foram produzidos, em média, 72 fillhotes em cada local atendido.

Ao considerar que os animais foram comercializados por $\mathrm{R} \$ 20,00$, as pessoas assistidas puderam perceber que a criação desses animais demonstrou ser mais uma alternativa de geração de renda. Isso porque o custo de produção foi muito pequeno dentro do sistema de criação proposto, o que proporcionou uma boa margem de lucro.

Todo o sistema de instalação para os coelhos foi montado totalmente rústico, cada animal sendo alojado individualmente em cada coelheira, construída com sobras de material como tábuas, ripas e pedaços de telhas de amianto, em local com sombra e acima do nível do chão. Com um piso vazado para a queda das excretas destes animais, tendo a ideia de evitar o contato direto de fezes e urina com cada um, foi utilizada também uma sombrite para possibilitar a proteção contra o vento, com a importância de serem ventiladas no verão e protegidas no inverno.

Nesse caso o ninho foi construído totalmente de madeira, com o formato de uma caixa fechada de 50x30x30, com uma abertura nas extremidades de 15x15, para evitar ao máximo a perda de calor desses filhotes, como recomendado por Brum Jr. et. al. (2012).

Sendo uma ação totalmente sustentável, pensando nisso, os bebedouros e comedouros são do tipo "pote de plástico".

Os participantes tiveram a orientação para utilizarem ração em pequenas quantidades e fornecer também forrageiras in natura, além do uso de fonte de energia, como por exemplo: tubérculos e raízes provenientes da horta, e outras hortaliças herbáceas como couve e rama de batata doce, lembrando que estes resíduos são insetos de herbicidas/pesticidas. Os mesmos foram orientados a remover as sobras antes do reabastecimento para evitar fermentação e rejeição dos animais. A alimentação dos animais foi dividida em três refeições, fornecida nos períodos da manhã, da tarde e da noite, também foi realizada de acordo com a fase em que o animal se apresentava, como por exemplo: manutenção gestação e lactação.

Esses assentados e os colaboradores da escola tiveram o papel fundamental da produção de hortaliças, com base nas técnicas da produção orgânica.

A introdução desta ação extensionista na escola se mostrou relevante no aspecto educacional e de difusão, aumentando assim o interesse dos alunos, que em sua maioria é oriundo de famílias da agricultura familiar de baixa renda, que até então não possuíam interesse e nem tampouco entendimento sobre a criação racional, produtiva e econômica dos coelhos. Estas famílias 
viram na atividade cunícula, uma possibilidade de melhorar sua rentabilidade e se tornarem empreendedores. Tendo o objetivo de transformar as hortaliças descartadas das hortas, em uma fonte de alimentação para os coelhos.

Para que tenha continuidade e que haja evolução na cunicultura, os novos criadores tiveram oportunidade de sanar suas dúvidas durante o acompanhamento da execução das atividades e durante as explanações teóricas. Frente a isso foi explicado que dependendo da tecnologia empregada, da nutrição, do manejo adotado e da genética utilizada, consegue-se imprimir o ritmo reprodutivo das matrizes do plantel (BRUN JR. et al., 2012). Esse ritmo pode variar de partos com intervalos de 40 dias até partos com intervalos de 90 dias. Nas situações em questão que a matriz é alimentada com ração comercial e suplementada com forrageiras, pode-se utilizar um programa reprodutivo em que o desmame ocorra aos 30 dias e o acasalamento da matriz seja realizado no dia do desmame. E ao reproduzir os animais a intenção era manter em torno de $5 \%$ dos filhotes para aumentar e melhorar o plantel e os demais serem comercializados para ajudar na compra de concentrado e materiais para melhorias das instalações, como exemplo, a obtenção de gaiolas padronizadas.

\section{Conclusão}

A cunicultura pode ser implantada com uso de alimentos alternativos em sua dieta e deve ser incentivada em assentamentos e escolas como alternativa de produção de uma fonte de proteína animal de qualidade e econômica, assim como de geração de renda.

Vale ressaltar que sistema recomendado, o manejo e a linguagem utilizada devem ser adaptados a realidade do público a ser atingido, diferenciando-se do preconizado para uma criação comercial.

\section{Agradecimentos}

À Pró-Reitoria de Extensão e Cultura da Universidade Federal da Grande DouradosUFGD, ao Núcleo de construção participativa do conhecimento em Agroecologia e Produção Orgânica; ao Centro vocacional tecnológico em Agroecologia e Produção Orgânica, em Mato Grosso do Sul, CNPq.

\section{Referências}

(ACBC) ASSOCIAÇÃO CIENTÍFICA BRASILEIRA DE CUNICULTURA. Disponível em: 


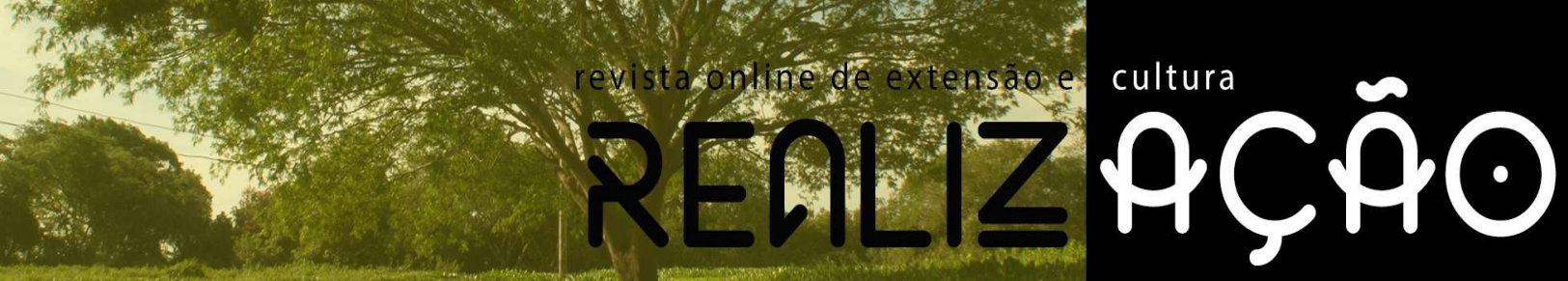

http://www. Acbc.org. br/. Acesso em: 22 jun. 2018.

ALMEIDA, D. G. de; SACCO, S. R. Estudo da viabilidade técnica e econômica para implantação da cunicultura em pequena propriedade rural. Revista Perspectiva em Gestão, Educação \& Tecnologia, Itapetininga, v. 1, n. 1, p.1-9, 2012. Semestral.

BRUM JR, B.S.; PELleGRINI, L. G.; SILVA, E. S.; SILVA, M. C. B.; LIMA, Q. T.; PELLEGRINI, A. C. R. S.. Implantação da cunicultura como uma alternativa de produção de proteína animal para a comunidade carente de São João do Barro preto Revista Brasileira de Cunicultura, v.2, n. 1, Setembro de 2012 - Disponível em http://www.rbc.acbc.org.br/index.php? option $=$ com_content $\&$ view $=$ article $\&$ id $=63 \&$ Itemid $=71$

FABICHAK, I. Coelhos: Criação Caseira. São Paulo: NBL, 2005.

JEZINE, E. As práticas curriculares e a Extensão Universitária. In: $2^{\circ}$ CONGRESSO BRASILEIRO DE EXTENSÃO UNIVERSITÁRIA. Belo Horizonte. Anais...., Belo Horizonte, 12 a 15 de setembro de 2004.

LUKEFAHR, S. D. Sustainable and alternative systems of rabbit production. In: 8 TH WORLD RABBIT CONGRESS, 8., 2004, Puebla. Anais... Puebla: México, 2004.

MACHADO, L. C.. Opinião: Panorama da cunicultura Brasileira. Revista Brasileira de Cunicultura, Bambuí (MG), v. 2, n. 1, set. 2012.

MACHADO, L. C.; FERREIRA, W.M. A cunicultura e o desenvolvimento sustentável. Associação cientifica brasileira de cunicultura. IFMG, campus Bambuí, Minas Gerais, 2011.

FERREIRA, W.M.; SARTORI, A.L.; SANTIAGO, G. S.; et al.. Digestibilidade aparente dos fenos de rami (Boehmeria nivea, G.), guandu (Cajanus cajan, L.), soja perene (Glycine wightii, V.) e da palha de feijão (Phaseolus vulgaris, L) em coelhos na fase de crescimento. Arquivo Brasileiro de Medicina Veterinária e Zootecnia, v.49, n.4, p.465-472, 1997.

LUZZI, N. O debate agroecológico no Brasil: uma construção a partir de diferentes atores sociais. Tese de Doutorado Ciências Sociais em Desenvolvimento, Agricultura e Sociedade, Universidade Federal do Rio de Janeiro, Itaguaí, 1997.

OLIVEIRA, C. E. A. Dietas simplificadas na alimentação de coelhos e seus efeitos na reprodução e produção. Tese de Doutorado, Escola de Veterinária, Universidade Federal de Minas Gerais, belo Horizonte, 2009.

OSENI, S.O. Rabbit production in low-input systems in Africa: prospects, challenges and opportunities. In: 10 TH WORLD RABBIT CONGRESS, 10, 2012, Sharm El- Sheikh. Proceedings.... Egito: World Rabbit Science Association, 2012. p. 719 - 731.

SCAPINELlO, C.; FALCO, J. E.; FURLAN, A. C.; FARIA, H. G.. Desempenho de coelhos em crescimento alimentados com diferentes níveis de feno da rama da mandioca (Manihot esculenta, CRANTZ). Ciência Rural, Santa Maria, v.30, n.3, p.493-497, 2000. 
SANTOS, R. M. M. G.; COSTA, R. G.; SILVA, J. H. V.; MEDEIROS, A. N.; CARREGAL, R. D.; SANTOS, E. A.; TEIXEIRA, E. N. M.. Efeito da substituição da proteína do farelo de soja pela proteína do feno de amoreira (Morus alba) na dieta de coelhos em crescimento. Agropecuária Técnica, v.27, n.1, p.49-52, 2006.

SCHIERE, J. B.; CORSTIAENSEN, C. J. Criação de coelhos em quintais, nas regiões tropicais. Agrodok 20, Fundação Agromisa e CTA, Wageningen, 2008. 84 P.

VIEIRA, M. I.. Carne de Coelho. Rural News 2008. Disponível em: $<$ http://www.acbc.org.br/images/stories/Manual_prtico_de_cunicultura_2_parte>. Acesso em: 25 jun. 2016.

VIEIRA, J. S.; Marli Arena DIONÍZIO, M. A.; N. PEREIRA, R. A. N.; SANTOS, E. C.. Manual de utilização de subprodutos de coelhos. Disponível em: http://www.editora.ufla.br/index.php/component/phocadownload/category/56-boletins-de-extensao? download=1174:boletinsextensao. Acesso em 25 e jun. 2016. 